\title{
Jogos-rituais na encruza: pesquisa performática entre feminismos decoloniais e ancestralidade
}

\author{
Ritual Games at the Crossroads: Performance Research Between \\ Decolonial Feminisms and Ancestry
}

Juegos rituales en la encrucijada: investigación escénica entre feminismos descoloniales y ascendencia

Mariana de Queiroz Cezar (Universidade Federal Fluminense, Brasil) *

https://doi.org/10.22409/poiesis.v22i37.44461

\begin{abstract}
RESUMO: Este artigo trata de uma pesquisa performática em processo de criação de jogos-rituais, entrelaçando vivências diárias com feminismos decoloniais, performance ritual e simbologias do número três intrínsecas à Exu. A partir de uma carta contínua endereçada a Gloria Anzaldúa, discorre-se como conceitos teóricos decoloniais se conectam com ações performáticas coletivas e aos princípios do orixá. O presente trabalho investiga a encruzilhada como expansão de possibilidades de ser mulher, utilizando a necessidade da enunciação de si sendo tão urgente para pensarmos arte, política e cotidiano na cena contemporânea latina.
\end{abstract}

PALAVRAS-CHAVE: ancestralidade; performance ritual; feminismos decoloniais

* Mariana de Queiroz Cezar é mestranda do Programa de Pós-Graduação em Estudos Contemporâneos das Artes da UFF. Cursou Arte dramática na ETET Martins Penna e Relações Internacionais na UFRJ. Orcid: https://orcid.org/0000-0002-7386-0170. E-mail: mariqueirozczar@gmail.com.

Revista Poiésis, Niterói, v. 22, n. 37, p. 281-298, jan./jun. 2021. (https://doi.org/10.22409/poiesis.v22i37.44461) 
ABSTRACT: This article deals with a performance research in the process of creating ritual games, intertwining daily experiences with decolonial feminisms, ritual performance and symbols of the number three intrinsic to Exu. From a continuous letter addressed to Gloria Anzaldúa, it is discussed how decolonial theoretical concepts are connected with collective performance actions and the principles of the orisha. The present work investigates the crossroads as an expansion of the possibilities of being a woman, using the need for self-enunciation being so urgent to think about art, politics and daily life in the contemporary Latin scene.

KEYWORDS: ancestry; performance ritual; decolonial feminisms

RESUMEN: Este artículo trata de una investigación de performance en el proceso de creación de juegos rituales, entrelazando experiencias cotidianas con feminismos decoloniales, performance ritual y símbolos del número tres intrínsecos al Exu. A partir de una carta continúa dirigida a Gloria Anzaldúa, se discute cómo los conceptos teóricos decoloniales se relacionan con las acciones de actuación colectiva y los principios del orixá. El presente trabajo indaga en la encrucijada como una ampliación de las posibilidades de ser mujer, utilizando la necesidad de auto enunciación tan urgente para pensar en el arte, la política y la vida cotidiana en la escena latina contemporánea.

PALABRAS CLAVE: ascendência; performance ritual; feminismos descoloniales

Recebido: 31/8/2020; Aprovado: 5/12/2020; Publicado: 2/1/2021.

Citação recomendada:

CEZAR, Mariana de Queiroz. Jogos-rituais na encruza: pesquisa performática entre feminismos decoloniais e ancestralidade. Revista Poiésis, Niterói, v. 22, n. 37, p. 281-298, jan./jun. 2021. [https://doi.org/10.22409/poiesis.v22i37.44461]

(cc) BY-NC-ND Este documento é distribuído nos termos da licença Creative Commons Atribuição-NãoComercial 4.0 Internacional (CC-BY-NC) (c) 2021 Mariana de Queiroz Cezar

Mariana de Queiroz Cezar, Jogos-rituais na encruza: pesquisa performática entre feminismos decoloniais... 


\section{Jogos-rituais na encruza: pesquisa performática entre feminismos decoloniais e ancestralidade}

Escrevam com seus olhos como pintoras, com seus ouvidos como músicas, com seus pés como dançarinas. Vocês são as profetisas com penas e tochas. Escrevam com suas línguas de fogo. Não deixem que a caneta lhes afugente de vocês mesmas. Não deixem a tinta coagular em suas canetas. Não deixem o censor apagar as centelhas, nem mordaças abafar suas vozes. Ponham suas tripas no papel.

--- Gloria Anzaldúa, 1980.
A força da pulsação do meu coração e a vibração da minha garganta que sinto ao cruzar exposições de eus, firmando pontos de conexão entre diferentes vias da minha existência na terra, me faz agradecer ao que me mantém em pé, viva e corajosa para ocupar o meu propósito de existência. O que sustenta essa força vital de realização, ação e voz no mundo é o axé, "força que assegura a existência dinâmica, que permite o acontecer e o devir. [...] É o princípio que torna possível o processo vital." (DOS SANTOS, 1997, p. 39) 
Juana Elbein dos Santos discorre sobre o axé em três pontos centrais: sua presença necessária em todas as coisas; suas possibilidades de expansão ou retração; e sua característica de poder ser transmitido entre as coisas existentes. Uma das linhas de condução dessa transmissibilidade do axé é através da ancestralidade, como costura entre os tempos para fortalecimento das nossas potencialidades, para sobrevivência presente e construção futura. Então, agradeço à toda nossa ancestralidade que nos trouxe até aqui e nos levará a muitos lugares mais. Nós as levaremos conosco também. Juntas, abrimos caminhos.

Para estar onde estamos, quantas mulheres transbordaram fronteiras? Abrir caminhos para quem vem é transmissão de axé. Quantas mulheres dedicaram suas vidas à transformação e à construção coletiva de futuros que hoje estamos vivendo? O que continuamos hoje? Para embarcar no tempo histórico da resistência é preciso pressa, porque estar nele é intrinsecamente ligado aos nossos viveres, saberes e memórias.
Escrevo hoje, em agosto de 2020, esta carta contínua para Glória Anzaldúa, buscando comunicação mais direta com essa costura do tempo como mais uma chance e tentativa de agradecimento, pertencimento e fortalecimento. Anzaldúa foi uma chicana entre-fronteiras (PALMEIRA, 2020) que mergulhou na escrita como forma de resistência, desenvolvendo uma teoria de existência nas fronteiras. Em maio de 1980, com Falando em línguas: uma carta para as mulheres escritoras do terceiro mundo, ela coloca suas tripas no papel e nos convida a formas de fazer com que esse ato de potência possa se entrelaçar ao cotidiano de sobrevivência e violência das mulheres latinas. Sua obra tem perspectiva mestiça, recebendo influência das fronteiras entre México e EUA, desdobrando questionamentos de como esse nãolugar se estende aos múltiplos aspectos de raça, gênero e até de nação. Anzaldúa entrega toda angústia e potência de olhar para si e ver tantas; em sentir um turbiIhão de possibilidades que não tem onde escoar; de poder aterrar vivências e coIher multiplicidades.

Mariana de Queiroz Cezar, Jogos-rituais na encruza: pesquisa performática entre feminismos decoloniais... 
Como nos atrevemos a sair de nossas peles?

Como nos atrevemos a revelar a carne humana

escondida e sangrar vermelho como os bran-

cos? É preciso uma enorme energia e coragem

para não aquiescer, para não se render a uma

definição de feminismo que ainda torna a

maioria de nós invisíveis. (ANZALDÚA, 1980, p. 231)

Nossa estrutura político-econômico-sociocultural é feita de obstáculos, feridas e opressões profundas que operam ativamente a cada movimento nosso. Abraçar o impulso permanente de transformação, que é próprio da vida, é contra hegemônico, já que o padrão é o da rigidez e engessamento das possibilidades, hierarquizando e silenciando existências através do sexismo e do racismo, bases do capitalismo. Sentimos sintomas dessa dinâmica perversa a todo tempo e cada passo que damos em direção a nós mesmas é uma ruptura com esse sistema. O caminho de volta é grande, mas a dor de não o refazer maior ainda.
São de dúvidas que me preencho a cada respiro nessa terra de certezas intransponíveis e excludentes. Dou-me chances de observar, criticar e transformar a cada detalhe cotidiano, pois são nas frestas que potencializamos nossa autonomia. Senão, quem sucumbe somos nós. Desacreditando na mudança e nos invisibilizando, embarcamos na falácia de uma universalidade do sujeito que só tem como objetivo nos inferiorizar. Anzaldúa conta-nos na carta detalhes do cotidiano que nos afastam de escrever para assim nos desnudar, para expandir, para existir para nós e para o mundo. Porque quando não somos visíveis no mundo, temos que nos esforçar mais para podermos enxergarmo-nos e para confiar na importância do que temos em nossos corpos para estarmos aqui.

As palavras não saem de mim, escritas nem faladas, senão muito pensadas, mas por que não dizer, um tanto medidas com medidores externos que encurtam minhas linhas/línguas pela metade e meu pensamento parece sem qualidade. É de início que logo uso meus subterfúgios: falar do macro e, agora, rimar. Fujo das sensações paradoxais que me apresentar me causam ou corro de encarar as vulnerabilidades 
que queimam quando chego mais perto. 0 que eu proponho pesquisar é diretamente ligado ao cerne de tudo que me move, no íntimo e no público. E, ainda agora, não consigo fugir da sensação de falta. Falta minha de desempenho, de valorização, de confiança. Escrevo como se tivesse me esquivando de uma bola em um jogo de queimado, ou como se estivesse em um labirinto no qual só ando nas bordas quando a saída está no meio.

Sinto palpitar descompassado o coração, encontrar um certo bambear nas pernas e me sinto enjoada, com uma bola de energia peluda e cinza acoplada no centro do meu peito. Minha garganta se estreita. Escrevo e tenho medo das palavras, corro por entre neblinas de metáforas. Me assusta pesquisar o movimento cíclico de vida e morte, destruição e criação, luz e escuridão. Mais ainda me assusta transitar através do entre nessas dimensões. Sentir meu cotidiano embalado e afetado por opostos me faz pesar para alguns lados, às vezes forte, grande e, outras vezes, um quase vazio. A dor de ter consciência dos apagamentos de partes de si mesma se faz presente no momento quando materializamos nossa expressão, desenhando a faca de dois gumes que é o exercício de escrever, criar e transformar a partir de quem somos. Hoje, a imagem que eu tenho de mim é: a minha mão sempre prestes a pegar um chicote/caneta. Eu, na iminência do passo para o abismo, preciso afiar minhas intuições frente aos medos diários de confiar e seguir minhas apostas, caminhos e sentidos.

\section{Feminismos decoloniais}

As maneiras pelas quais as teorias feministas decoloniais podem provocar, invocar, fortalecer um processo artístico transdisciplinar se estabelece como uma das questões centrais. Quais caminhos podemos percorrer através das diferenças decoloniais para resgatar partes nossas silenciadas/apagadas e, assim, buscar meIhor compreender nossos contextos complexos de mulheres latino-americanas para traçar futuros? Utilizar-se da decolonialidade como impulso para narrativas expandidas que multipliquem nossas possibilidades de ser mulher, que nos conecte com imagens e forças que também nos pertencem, mas que, ao longo de uma 
construção colonizadora de gênero e raça, nos foi negada.

Pensando, então, um recorte na pesquisa decolonial: para se revelar o escondido é necessário olhar para trás, é necessário resgatar memórias e vivências que no processo de colonização foram subjugadas, silenciadas e oprimidas, de muitas formas e em muitas camadas. Através desse movimento, experimentar na criação artística simbologias, elementos e saberes que resistem há muitas gerações, atravessando nossas ancestralidades.

Feminismos decoloniais são nomeclaturas para a crescente lista de feminismos póscolonialistas desde 1980 que, buscando frentes práticas e teóricas, foram impulsionados a criticar duramente as ondas do feminismo hegemônico apoiado em um recorte branco, localizado no norte do globo, ocidental, elitista e heterossexual como sendo pautado universal. Logo de cara deve-se colocar a importância da enunciação de si mesma como sujeito, ligando diretamente a vivência diária com a escrita e a produção de conhecimento acadêmico. É necessário sair da redoma sufocante de uma universalidade eu- rocêntrica para cair no abismo das fraturas coloniais que recaem sobre cada uma, costurando nossas próprias suturas entre cotidiano e pensamento.

Um dos motores centrais para autoras negras, latino-americanas, LGBTQAI+, indígenas, asiáticas, queer; mulheres subalternizadas pela hierarquia geopolítica é a questão: qual sujeito mulher? As condicionalidades e consequentes pautas apresentadas pelo feminismo branco permitiam a manutenção do status quo construído pela dominação e imposição da visão de mundo sustentada pela colonialidade do poder (QUIJANO, 2005). Um imaginário e um real estreitos em imagens que só refletiam uma pequena parcela de mulheres, corroborando em apagamentos e silenciamentos violentos de existências, histórias e pautas urgentes. Assim, é possível perceber como é necessária a valorização de saberes e vivências outras, fora da hierarquia dicotômica produzida pela colonização e, consequentemente, da situação coIonial gerada pelos ramos de controle da colonialidade, quanto à economia; autoridade, natureza e recursos, gênero e sexualidade; subjetividade e conhecimento. (GROSFOGUEL, 2007) 
Frestas para escapar da dicotomia de ser ou não ser. Estar entre um e outro é uma terceira via que dá na encruzilhada de múltiplas possibilidades de existir. Entre um e outro, ficamos com o entre. Porque é ele quem abre para a chance do constante movimento, da permanente mudança, que é tão intrínseco aos ciclos de vida-mortevida. Sentir-se mudança e acompanhar como se fosse uma dança não é tão fácil quanto na rima. A conexão com as potencialidades particulares de se sentir mulheres é desprezada por dominações coloniais que enrijecem e delimitam as experiências com nosso autoconhecimento.

Aníbal Quijano denominou colonialidade a lógica do poder colonial que segue operando e produzindo segmentações raciais, sociais e de gênero. A matriz de análise para o autor peruano é o conceito de Wallerstein de sistema-mundo, apontando a existência de fenômenos de dominação das forças de trabalho ligado à segmentação racial do mundo, gerando precarização da vida e hierarquias geopolíticas a partir das diferenças coloniais. É central entender a coetanidade entre modernidade e colonialidade, isto é, de que maneira esses dois fenômenos são simultâneos e interdependentes, estando seus surgimentos e suas temporalidades diretamente entrelaçados.

É necessário buscar o conceito de "colonialidade do poder" de Aníbal Quijano redesenhando assim as relações intersubjetivas e culturais entre a Europa Ocidental e o resto do mundo através de codificações em categorias bipolares: Oriente-Ocidente, primitivo-civilizado, mágico/mí-tico-científico, irracional-racional, tradicional-moderno. O autor aponta o evolucionismo e o dualismo como elementos focais do eurocentrismo, logo, parte do movimento de colonização da Europa e da Não-Europa. Se constituindo como uma forma de classificação de formas de existências, de culturas, de pessoas e hierarquizando as dicotomias para manter o próprio status quo com a inferioridade dos colonizados.

Dessa maneira, Quijano coloca à luz quantas camadas culturais, políticas e sociais foram abafadas por uma perspectiva hegemônica europeia, o eurocentrismo. Quijano discorre sobre como o atual padrão de poder é composto e, por isso, de que maneiras se forma um sistema articulado

Mariana de Queiroz Cezar, Jogos-rituais na encruza: pesquisa performática entre feminismos decoloniais... 
no âmbito da existência social. Apontando, assim, três elementos centrais que afetam a vida cotidiana da maior parte da população mundial: a colonialidade do poder, o capitalismo e o eurocentrismo. O autor apresenta entendimento histórico da inseparabilidade dos processos de racialização e de exploração capitalista, enraizada na colonização das Américas. Maria Lugones utiliza seu termo e dá continuidade.

Lugones usa o termo colonialidade para pensar o processo ativo de redução de pessoas, desumanização pela classificação, o processo de subjetivação. A colonização deixou conosco o que a autora chama de colonialidade dos gêneros, através da intersecção raça/classe/gênero como instrumento central do sistema mundial capitalista de poder. Nessa pesquisa artística buscamos o olhar da autora para as "diferenças coloniais" e deslocar nossas percepções às múltiplas subjetividades possíveis. Podemos identificar o lugar do lócus fraturado como o entre que destacamos também nas obras de Judith Butler e Luiz Rufino. Apontamos a presença das potências e das simbologias do número " 3 " como possível passo para sair das dicotomias hierarquizadas e para nos- sa expansão de possibilidades e olhares da existência social.

0 sujeito, as relações, as bases e as possibilidades são continuamente transformadas, encarnando uma trama desde o lócus fraturado que constitui uma recriação criativa, povoada. Adaptar, rejeitar, adotar, ignorar e integrar nunca são apenas formas isoladas de resistência, por serem sempre performadas por um sujeito ativo complexamente construído na sua habitação da diferença colonial com um lócus fraturado. Quero enxergar a multiplicidade dessa fratura: tanto a imposição da colonialidade dos gêneros quanto a resposta resistente de um subalterno senso de si, do social, do Eu relacional, do cosmos, todos baseados em uma memória povoada. (LUGONES, 2019, p. 372) 
Para Lugones, os movimentos de resistência à colonialidade são feitos de forma coletiva. Esses conceitos impulsionaram a criação do dispositivo performático de jogos-rituais como uma vivência compartiIhada com amplitudes particulares, um convite provocação para a observação de nossas próprias ações no mundo e o reconhecimento de possibilidades de expansão de potencialidades do ser. A importância dos caminhos abertos por Audre Lorde é central para a pesquisa no que se refere à necessidade de se conectar consigo para potencializar nossas forças vitais e alcançar possibilidades de fortalecimento coletivo, cultivando multiplicidades de ser, estar e viver. Além de colocar a ancestralidade como chave nesse processo. $O$ pensamento poético da autora caribenha-americana, assim como a premissa principal dos jogos-rituais, propõem a experimentação como maneira de percepção e dinâmica cotidiana em relação à vida como um todo, vivenciando uma busca de mais possibilidades e de menos certezas. Como ato performático, buscamos inserir esse aspecto na imprevisibilidade do momento frente à criação de espaços singulares, de observação particular de si.
É possível conectar as sensações ambíguas presentes no resistir apresentado por Maria Lugones às de Lorde acerca da importância da transformação dos silêncios em ação. É forte a maneira como Lorde afirma a faca de dois gumes, que é ter medo, mas precisar operar dessa forma por sua própria existência no mundo. Feminismos decolonais são construídos, e estão em construção, através do entrelaçamento da escrita com a vivência, da prática com a teoria. São costuras entre fraturas coloniais que expõem a intenção de vazio da multiplicidade de existências. São entres como esse que são motores para a investigação performática da pesquisa, buscando nas brechas para nossa autorrevelação o fortalecimento das nossas potências singulares dentro de tantas possibilidades de construções coletivas.

Práticas políticas feministas decolonais são exercícios constantes que perpassam várias camadas da vida, pulsando de forma integrada e em movimento permanente. Lorde afirma acima esses cruzamentos necessários para a percepção de epistemes outras, que não aquelas já fixadas como padrão, para a sobrevivência no patriarcado branco. Ao mesmo tempo, con-

Mariana de Queiroz Cezar, Jogos-rituais na encruza: pesquisa performática entre feminismos decoloniais... 
vida para essa jornada íntima de autoconhecimento e de busca ancestral para o nascimento de futuros outros.

\section{E, é claro que eu tenho medo, porque a trans- formação do silêncio em linguagem e em ação é um ato de autorrevelação, e isso sempre pa- rece estar cheio de perigos. Mas minha filha, quando falei de nosso tema e de minhas difi- culdades, me disse: "Fala para elas de como nunca se é uma pessoa inteira se guardas si- lêncio, porque esse pedacinho fica sempre dentro de ti e quer sair, e se segues ignoran- do-0, ele se torna cada vez mais irritado e fu- rioso, e se nunca o deixar sair um dia diz: bas- ta! e te dá um soco dentro da boca". No silên- cio, cada uma de nós desvia o olhar de seus próprios medos - medo do desprezo, da cen- sura, do julgamento, ou do reconhecimento, do desafio, do aniquilamento. Mas antes de nada acredito que tememos a visibilidade, sem a qual entretanto não podemos viver, não podemos viver verdadeiramente. (LORDE, 2019, p. 51)}

Pensando nesse movimento de expansão das possibilidades de encontro e das multiplicidades da presença coletiva, através de exercícios performáticos na criação de jogos-rituais, investigamos os caminhos para potencializar as singularidades na coletividade. Há intenção política de valorizar a multiplicidade através de dinâmicas que abram espaço de confiar em si e nos nossos instintos mais selvagens, genuínos. Judith Butler aponta uma rejeição dessa multiplicidade das interseções culturais, sociais e políticas por uma insistência sobre uma coerência e unidade da categoria "mulheres". Em seu livro Problemas de gênero: feminismo e subversão da identidade, a autora apresenta problemáticas da teoria feminista que se pretende única e assim não alcança camadas de possibilidades. Restringir em definições unificadas é limitador e despotencializa tanto as singularidades possíveis da expansão coletiva quanto a luta política.

Atentando a essa questão, convocamos aspectos do número "3" para criação de jogos-rituais performáticos com o interesse de fortalecimento das potências pessoais em um exercício coletivo, de conexão e presença plural. 0 " 3 " traz a comunicação, o desequilíbrio, as possibilidades de movimento, o não-dualismo e a incompletude que se fazem necessários para expandir as perspectivas e as ações de existências. 
Conecto esse ponto diretamente ao cerne da questão do primeiro capítulo do livro de Butler:

\section{A hipótese de sua incompletude essencial permite à categoria servir permanentemente como espaço disponível para os significados contestados. A incompletude por definição dessa categoria poderá, assim, vir a servir co- mo um ideal normativo, livre de qualquer for- ça coercitiva. (BUTLER, 2003, p. 40)}

O interesse de criar um ato performático que seja uma experiência coletiva para potencializar as diferenças, dando espaço para variáveis de acordo com as e os participantes é buscar, através de jogosrituais, envolver construções e intuições pessoais em conexão com possibilidades de presenças coletivas. O entrelaçamento dos elementos no processo de criação tem acontecido através dos estudos de simbologias do número " 3 " e da investigação por presenças da coletividade para provocar imprevisibilidades dentro da performance. Cada etapa desse jogo-ritual somente pode acontecer com um pouco de cada um/uma dos presentes, em potência de corpo, respiração, olhar, verbos, perguntas. Como experimentar o mesmo jogo-ritual em vários contextos, lugares, pessoas visando múltiplas vivências é instigante para pensar a multiplicidade dos encontros?

É possível apontar uma ponte entre a visão de Butler com a apresentada por Luiz Rufino no livro Pedagogia das encruzilhadas. Rufino afirma que o princípio de Exu ao ser invocado, por ser uma potência indisciplinável e incontrolável, faz com que seja necessário considerar outras lógicas, sendo elas dadas pela diferença cultural.

\section{Exu é aquele que, para ensinar os homens, prega peças, desautoriza todos aqueles que se acomodam sobre presunção de uma verdade limitadamente acabada. É ele o princípio da imprevisibilidade que utiliza da astúcia da aparência, o correlacionando ao sentido de re- alidade. É ele que pune qualquer forma de ob- sessão pela certeza, instaurando a dúvida. Exu esfera de saber potencialmente emancipató- ria, pois é o próprio movimento e, por não ter arestas, é dificilmente apreendido: ao colidir com algo, se transforma em um terceiro ele- mento, não mais o primeiro ou segundo, mas um terceiro, um entre. (RUFIN0, 2019, p. 53)}


Butler também busca outras vias para sair da binariedade, expressando a importância de uma coalizão aberta que permita a expansão das possibilidades e que não delimite certezas, assim como Rufino falando das potências de Exu; a autora vibra pelas dúvidas frente às tentativas de identidades enrijecidas. Buscamos conexão no entre das diferenças teóricas e culturais dos dois autores para afirmar a potencialidade existente justamente no espaço liminar da criação de jogos-rituais coletivos na pesquisa performática.

A pesquisa artística sobre as simbologias do número " 3 " se revelou no processo de criação através de intuições e de uma crescente inquietude provocada por bibliografias acerca da estrutura binária da construção ocidental de oposição, como corpo/mente, feminino/masculino e emoção/razão. As teorias decoloniais localizam camadas de construção que cada sujeito tem sobre si através da geopolítica, analisando historicamente de que maneira a colonização enrijeceu, oprimiu e dizimou possibilidades de ser, viver e construir. Segundo Maria Lugones, "a dicotomia hierárquica como uma marca de humanidade também se tornou uma ferra- menta normativa de condenação dos colonizados." (2019, p. 359)

As potências e simbologias do número " 3 " vieram como intuição logo no início do processo acadêmico, assim como faz Exu, e veio se colocando na pesquisa através de frestas, de entres, suscitando a encruza do autoconhecimento para fortalecimento das nossas singularidades encarnadas. Pensar o "3" como um disparador de possibilidades, através da investigação dos seus aspectos, simbologias e práticas, buscando instrumentalizá-lo como resistência decolonial. Maria Lugones afirma a importância do movimento de revelar o que está escondido, de expandir as percepções das camadas culturais, sociais, espirituais com as quais estamos envolvidos e como, ao mesmo tempo, estamos inseridos em uma construção ocidental que para se experimentar o que se é necessita resistência. 
A resistência é a tensão entre a subjetivação(a formação/ informação do sujeito) e a subjetividade ativa, 0 senso mínimo de agência necessário para que a relação oprimir -><- resistir seja ativa, sem recorrerão senso máximo de agência da subjetividade moderna.

(LUGONES, 2019, p. 362)

Assim, a centralidade do " 3 " para a criação dos jogos-rituais é um exercício de alargamento da comunicação, da expressão criativa e do fortalecimento da multiplicidade de resistências. Muito nos desafia e interessa pesquisar caminhos de vivências da teoria, de maneira que é instigante criar dinâmicas através do motor da ruptura com a rigidez da binariedade e a dicotomia hierárquica dos poderes.

\section{Performance ritual}

A pesquisa busca a ampliação de singularidades para fortalecimento coletivo através da investigação performática de jogos-rituais na encruza. Emaranhados para ritualizar autonomias através de simbolismos, afiando formas de se ouvir e de potencializar nosso cotidiano. São artísti- cos, políticos e espirituais aspectos que se cruzam nesta experimentação coletiva, mas singular.

As bases de criação para os jogos-rituais entrelaçam alguns pontos referentes à performatividade ritualística. Leda Maria Martins, em Afrografias de memórias, investiga as camadas sobrepostas presentes na performance através do estudo profundo das religiões de matriz africana Congados e Reinado.

A performance ritual é, pois, um ato de inscrição. Nas culturais predominantemente orais e gestuais, como as africanas e as indígenas, por exemplo, 0 corpo é, por excelência, o local da própria memória, 0 copo em performance, 0 corpo que é performance. Como tal esse corpo/corpus não apenas repete um hábito, mas também institui, interpreta e revisa no ato reencenado. Daí a importância de ressaltarmos nas tradições performáticas sua natureza meta-constitutiva, nas quais o fazer não elide 0 ato de reflexão; 0 conteúdo imbrica-se na forma, a memória grafa-se no corpo, que a registra, transmite e modifica dinamicamente. 0 corpo, nessas tradições, não é, portanto, apenas extensão de um saber representado, e nem arquivo de uma cristalização estática. Ele

Mariana de Queiroz Cezar, Jogos-rituais na encruza: pesquisa performática entre feminismos decoloniais... 
é, sim, local de um saber em contínuo movimento de recriação formal, remissão e transformações perenes do corpus cultural. (MARTINS, 1997, p. 78)

Com essa proposição de Martins é possível fazer o paralelo com o conceito de liminaridade utilizado por Turner (1974) e Schechner (2012), como é apontado na análise comparativa de Grasielle Aires da Costa. No ritual as fronteiras e limites do tempo - espaço se destacam do cotidiano. A definição de ritual como "memórias de ação" (SCHECHNER apud COSTA, 2013) também inclui esse movimento gerado pelo ato ritual em todos os elementos, objetos, símbolos ou códigos presentes. Essa ideia de memória viva se conecta diretamente com a colocação de Leda Martins de que costurar os fios da memória também escreve histórias.

A imagem desse ir ao passado para construir futuros dentro de uma intenção colocada em um determinado tempo e espaço específico é o desenho da temporalidade espiralada no qual os eventos desembocam em transformações, que Martins desenvolve ao falar das possibilidades de re- arranjos filosóficos, espirituais, sociais que os sujeitos envolvidos podem passar através da experiência do ritual.

\section{Encruzilhada - Laroyê!}

Será que existe ainda alguma aleatoriedade de coincidências quando começamos a vivenciar nossas experiências diárias e artísticas com a percepção das potentes possibilidades da intencionalidade que alimentar nossa intuição produz em nossos caminhos? Intuição é ouvir sussurros surpresas, é seguir impulsos profundos e é permitir sair-se do controle racional para receber vozes e autonomias presentes em nosso entorno. Segundo Juana Elbein dos Santos, na cultura Yoruba a simbologia do número "3" pode ser apresentada como: 
petidas as invocações e as ações na pratica ritual. (SANTOS, 1997, p. 68)

A centralidade das simbologias e aspectos do número "3" foram crescendo na presente pesquisa através da experimentação prática de desdobramentos do número em dinâmicas performáticas e no conceito de "pedagogia das encruzilhadas", de Luiz Rufino. O autor conecta diretamente o número "3" ao orixá e princípio dinâmico da comunicação e da expansão Exu. Juana Elbein dos Santos se dedica ao entendimento de Exu como princípio dinâmico e de existência individualizada para o Sistema Nagô, especialmente na qualidade de Exu Bara. A autora explica o aspecto de " +1 ", pois tudo que existe tem seu próprio Exu, logo é sempre já contando com mais ele. Ela também aponta como essa adição de mais uma unidade evoca a continuação, o movimento constante e o inacabamento.

A ideia de "cruza" funciona como invocação de todos os caminhos possíveis de possibilidades, transitando pelos mundos material, imaterial e espiritual. O intuito principal desse processo artístico de cria- ção de jogos-rituais é expandir espaços para a imprevisibilidade coletiva, atentando que, para funcionar, precisa de uma multiplicidade de caminhos de fortalecimento das singularidades. Experimentar dinâmicas com elementos do jogo e do ritual para investigar desdobramentos imprevisíveis a partir de deslocamentos das lógicas estabelecidas em relação às camadas de existência. No que se refere a como nos colocamos no mundo, potencializar nossa escuta conosco sobre intuições e ações como cura às dicotomias hierarquizadas que oprimem possibilidades de ser. E assim, atingem não só o singular, mas também o funcionamento do todo.

O quanto de caminho tem custado à sola dos nossos pés a constante busca de equilíbrio na corda bamba da dicotomia de viver, ser, criar em um sistema construído e mantido pela colonialidade do poder? A regra de dois necessária para sustentar o jogo de poder da colonização é equação básica para engessar possibilidades de vida, pois coloca como base epistemológica a binariedade. $\mathrm{O}$ eu e o outro; espírito e corpo; feminino e masculino; branco e não-branco; ciência e não-ciência; teoria e prática; bem e mal; sujeito e objeto. $\mathrm{O}$

Mariana de Queiroz Cezar, Jogos-rituais na encruza: pesquisa performática entre feminismos decoloniais... 
pensamento dicotômico nos divide, nos torna chapados em dois lados. Encontro na potencialidade da encruzilhada, prática e caminho para decolonização cotidiana, para pensar multiplicidade no uno, para o inconformismo diante das consequências da colonialidade, assim como também encontrar esperança ao combater o esquecimento através da ancestralidade como possibilidade de vida.

A cultura negra também é, epistemologicamente, 0 lugar das encruzilhadas. 0 tecido cultural brasileiro, por exemplo, deriva-se dos cruzamentos de diferentes culturas e sistemas simbólicos, africanos, europeus, indígenas e, mais recentemente, orientais. [...] A noção de encruzilhada utilizada como operador conceitual, oferece-nos a possibilidade de interpretação do trânsito sistêmico e epistêmico que emergem dos processos inter e transculturais, nos quais se confrontam e se entrecruzam, nem sempre amistosamente, práticas performáticas, concepções e cosmovisões, princípios filosóficos e metafísicos, saberes diversos, enfim. (MARTINS, 1997, p. 69)
É na encruzilhada que os jogos-rituais acontecem, com o intuito de resgatar a expansão de possibilidades que acompanham nossa ancestralidade, no sentido de convocar as potencialidades de encontros, de criatividade, de comunicação que são intrínsecos da energia dinâmica de Exu, o dono da encruzilhada. O entendimento da importância de investigar a multiplicidade de saberes da encruza é central para o entrelaçamento com ações práticas feministas decolonais, no que se refere à expansão das possibilidades de existências, incluindo inscrições do sujeito "mulher". 
Referências

ANZALDÚA, Glória. Falando em outras línguas: carta às mulheres escritoras do terceiro mundo. Estudos Feministas, Florianópolis, ano 8, jan./jun. 2000.

BUTLER, Judith. Problemas de gênero: feminismo e subversão da identidade. São Paulo: Civilização Brasileira, 2003.

COSTA, Grasielle Aires da. O conceito de ritual em Richard Schechner e Victor Turner: análises e comparações. Revista Aspas, v. 3, n. 1, p. 49-60, 2013. Recuperado de http://www.revistas.usp. br/aspas/article/view/68385. Acesso em 30/6/ 2020.

GROSFOGUEL, Rámon. Descolonizando los universalismos occidentales: el pluriversalismo transmoderno decolonial desde Aimé Césaire hasta los zapatistas. El-GiroDecolonial. Bogotá: Siglo del Hombre Editores; Universidad Central, Pontifícia Universidad Javeriana. 2007.

LORDE, Audre. Irmã Outsider. São Paulo: Autêntica, 2019.

LUGONES, Maria. Rumo a um feminismo decolonial. In: Pensamento feminista. Rio de Janeiro: Editora Bazar do Tempo, 2019.
MARTINS, Leda Maria. Afrografias da memória. São Paulo: Editora Perspectiva. 1997.

QUIJANO, Aníbal. Colonialidade do poder, Eurocentrismo e América Latina. Buenos Aires: CLACSO 2005.

RUFINO, Luiz. Pedagogia das encruzilhadas. Rio de Janeiro: Mórula Editorial, 2019.

SANTOS, Juana Elbein dos. Os Nàgô e a morte: Pàde, Àsèsè e o Culto Égun na Bahia. Petrópolis: Editora Vozes, 1997.

SARAIVA PALMEIRA, Lara Virgínia. Glória Anzaldúa, uma chica entre-fronteiras.

Equatorial, Revista do Programa de PósGraduação em Antropologia Social (Dossiê: Gênero, deslocamentos e fronteiras no/do mundo contemporâneo), v. 7, n. 12, p. 1-20, 27 fev. 2020.

Mariana de Queiroz Cezar, Jogos-rituais na encruza: pesquisa performática entre feminismos decoloniais... 